\title{
Hot Deformation Characteristics of Si-Mn TRIP Steels with and without Nb Microalloy Additions
}

\author{
A. Zarei HANZAKI, P. D. HODGSON ${ }^{1)}$ and S. YUE \\ Department of Mining and Metallurgical Engineering, McGill University, Montreal, Canada. \\ 1) BHP Research, Melbourne Laboratories, Australia.
}

(Received on November 15, 1994; accepted in final form on December 16, 1994)

\begin{abstract}
It has been long recognized that steels with high formability and strength can be produced with the aid of the deformation induced transformation of retained austenite to martensite. Selecting the steel composition and microstructure to obtain significant amounts of retained austenite has been the first step in designing TRIP steels. Thus, it is now well established that a significant amount of retained austenite can be obtained in steels containing high concentrations $(>1 \%)$ of $\mathrm{Si}$, where bainite is one of the main microconstituents.

The effects of different intercritical annealing conditions on various aspects of Si-Mn TRIP steels have been extensively studied in other investigations. The present work was, however, conducted to investigate the influence of thermomechanical processing on the general behaviour of two Si-Mn TRIP steels, including a microalloyed $\mathrm{Nb}$-bearing grade. The effects of microstructural features produced by dynamic recrystallization and pancaking of austenite, along with that finishing temperature below the $T_{n r}$ (the austenite no-recrystallization temperature) on the subsequent transformations of the parent austenite, and the state of retained austenite at room temperature, were examined. It was found that, for microstructures compised of polygonal ferrite, bainite and retained austenite, the variation of the retained austenite volume fraction with strain in the no-recrystallization region exhibits a maximum. Furthermore, the dynamically recrystallized austenite substructure, when retained to transformation temperatures, tends to retain more austenite.
\end{abstract}

KEY WORDS: hot deformation; TRIP steels; retained austenite; thermomechanical processing (TMP); dynamic recrystallization and pancaking.

\section{Introduction}

In general, optimization of mechanical properties in metals and alloys can be achieved by alloying, in conjunction with heat treatment or thermomechanical processing. In steels, various types of compositions and heat treatments have been utilized to improve strength. However, alloying and heat treatments to improve strength are usually accompanied by lower ductility, i.e. there is frequently a compromise between strength and ductility. Therefore alternative methods which can result in the simultaneous improvement of both properties have been investigated. The corner stone of one of these approaches was laid by Zackay et al. ${ }^{11}$ They proposed that the strain or stress induced transformation of any retained austenite present in the microstructure to martensite can significantly strengthen the deforming alloy, and therefore result in higher ductility. This is the basic principle of Transformation Induced Plasticity (TRIP) effects.

Employing the TRIP phenomenon to produce steels with higher strength without loss of formability has been the subject of many recent investigations. ${ }^{2-5)}$ The majority of the studies, concentrating on $\mathrm{Si}(1-2 \%)$
$\mathrm{Mn}(1-2 \%)$ steels, have capitalised on the benefits of the presence of bainite in the microstructure. In this way, a new class of high formable steels has been developed, which can be significantly strengthened by deformation induced transformation of retained austenite to martensite. Since these grades of $\mathrm{Si}-\mathrm{Mn}$ steels are designed to contain retained austenite in order to achieve TRIP properties, they have been classified as TRIP steels. ${ }^{6}$ )

$\mathrm{Si}-\mathrm{Mn}$ bainitic TRIP steels in the form of sheet can be used mostly in the automotive industries, such as automatic structural press forming parts, bumpers, reinforcement parts, doorguard bars, etc. ${ }^{7)}$ The production of $\mathrm{Si}-\mathrm{Mn}$ TRIP steels in the form of bar and rod to make, for example, high strength fasteners, (bolts, nuts, studs, sterring links, tie rods, etc.), is also promising.

The steels for these applications must possess high strengths and good formability. For some forming operations, e.g. press forming, formability in TRIP steels can be evaluated by the product of tensile strength and total elongation, (TS $\times$ T.EL). The higher the value of this parameter, the better the formability. If the volume fraction of microstructural components (e.g., bainite, ferrite and retained austenite) is kept the same, the highest 
value of TS $\times$ T.EL is obtained when the retained austenite stability is optimised.

The present study concerns the control of the microstructure by thermomechanical processing (TMP) in order to attain the optimum conditions (size, distribution, quantity, composition and morphology) of retained austenite in $\mathrm{Si}-\mathrm{Mn}$ TRIP steels. Although TMP is a powerful method to control microstructure, its application to TRIP steel processing has yet to be investigated systematically. This paper details the effects of microstructural features produced by dynamic recrystallization and pancaking of austenite on the subsequent transformations of the parent austenite, and hence the state of retained austenite at room temperature.

\section{Experimental Procedure}

Table 1 shows the composition of the steels which were used in this study. These steels were received in the as hot rolled condition, from which specimens were machined. The only difference between these compositions is $\mathrm{Nb}$ in steel $\mathrm{A}$. The silicon in these steels exerts a retarding effect on the carbide precipitation from austenite. The resulting carbon enrichment of the austenite adjacent to ferrite plates in this way leads to more retained austenite in these grades of TRIP steels. $\mathrm{Nb}$ was originally added to steel $\mathrm{A}(\mathrm{Nb}$-steel) to raise the austenite no-recrystallization temperature and enable the steel to be processed by a variety of TMP routes, leading to both recrystallized and pancaked austenite prior to the austenite transformation.

All the mechanical experiments were carried out on a computerized materials testing system, adapted for hot compression tests, which is described in Ref. 8). The retained austenite measurements were performed by $X$-ray diffraction, as detailed in Ref. 9). The techniques used led to an accuracy of $\pm 2 \%$ in the amount of retained austenite. The X-ray data were also used to determine the carbon concentration in the retained austenite. The austenite lattice parameter extrapolation method, together with the following empirical expression,

Table 1. Chemical compositions of experimental steels.

\begin{tabular}{lcccccc}
\hline Composition & $\mathrm{C} \%$ & $\mathrm{Si} \%$ & $\mathrm{Mn} \%$ & $\mathrm{Nb} \%$ & $\mathrm{Al} \%$ & $\mathrm{~N}(\mathrm{ppm})$ \\
\hline Steel A (Nb-steel) & 0.22 & 1.55 & 1.55 & 0.035 & 0.028 & $20-40$ \\
Steel B (Reference-steel) & 0.19 & 0.150 & 1.54 & - & 0.024 & $20-40$ \\
\hline
\end{tabular}

Table 2. Critical temperatures of experimental steels.

\begin{tabular}{lll}
\hline Grade & Nb-steel Reference-steel \\
\hline $\begin{array}{lll}\text { No-recrystallization temp. } \\
\left(T_{n r},{ }^{\circ} \mathrm{C}\right)\end{array}$ & $930 \pm 5$ & $910 \pm 5$ \\
$\begin{array}{l}\text { Austenite-to-ferrite transformation temp. } \\
\left(A r_{e},{ }^{\circ} \mathrm{C}\right)\end{array}$ & $755 \pm 5$ & $750 \pm 5$ \\
$\begin{array}{l}\text { Start of acicular ferrite formation temp. } \\
\left({ }^{\circ} \mathrm{C}\right)\end{array}$ & $625 \pm 5$ & $650 \pm 5$ \\
$\begin{array}{l}\text { Austenite-to-pearlite transformation temp. } \\
\left(A r_{1},{ }^{\circ} \mathrm{C}\right)\end{array}$ & $590 \pm 5$ & $650 \pm 5$ \\
\hline
\end{tabular}

was employed to calculate the carbon content. ${ }^{9)}$

$$
a_{0}=3.578+0.044 \% \mathrm{C}
$$

The mechanical properties at room temperature were determined using a small specimen test technique, ${ }^{10}$ ) which was based on punching a $3 \mathrm{~mm}$ diameter disk out of a thin (300-350 $\mu \mathrm{m}$ thick specimen) while measuring the load/displacement behaviour on an MTS machine. Test caliberation was accomplished by comparing the results with those of conventional tension tests on the same steels. ${ }^{6)}$

For the purpose of designing TMP schedules, knowledge of the $T_{n r}, A r_{3}$ and $A r_{1}$, which are the no-recrystallization temperature, and the start and finish temperatures of the austenite-to-ferrite transformation, respectively, is required. These temperatures were measured by continuous cooling compression (CCC) testing. ${ }^{11)}$ The corresponding critical temperatures of steels $\mathrm{A}$ and $\mathrm{B}(\mathrm{Nb}-$ and Reference steels) are given in Table 2. As can be seen, the transformation characteristics of the $\mathrm{Nb}$-steel were significantly affected by the presence of $\mathrm{Nb}$.

\section{Parameters Affecting th Austenite Stability}

One of the measures of stability of austenite, which has been commonly accepted, is the martensite-start $\left(M_{s}\right)$ temperature. A low $M_{s}$ temperature is indicative of high austenite stability, i.e., high resistance to martensitic transformation. Generally, austenite stability has been shown to depend on austenite composition, ${ }^{12)}$ the size of austenite at the time of transformation (particle size effect), ${ }^{13)}$ austenitizing parameters, ${ }^{14)}$ cooling rates, ${ }^{15)}$ specimen thickness, ${ }^{12)}$ applied stress, ${ }^{16)}$ pressure, ${ }^{17)}$ austenite-to-martensite-to-austenite reverse cycling, ${ }^{18)}$ and thermal arrest (thermal stabilization) whilst cooling. ${ }^{19)}$

Austenite stability, in fact, can be considered to influence the kinetics of the martensitic transformation, in that it can effectively retard the nucleation and propagation events. Thus, the fundamentals of the mechanisms of austenite stabilization are based on how the aforementioned parameters may influence the nucleation and growth of martensite. Since the martensitic transformation progresses by shear, the rate of martensite formation is lower when the austenite resistance to shear is higher. Microscopic features, such as grain size and austenite fragmentation, as well as submicroscopic characteristics, such as the nature and distribution of defects, have been invoked to qualitatively explain austenite stability. The mechanisms appropriate to the present findings will be covered more deeply at the appropriate points in the discussion.

\section{Results and Discussion}

\subsection{The Effect of Dynamic Recrystallization}

As is well known, dynamic recrystallization (i.e., recrystallization under concurrent straining) is observed in FCC metals and alloys (except aluminum) containing moderate to low stacking-fault energy, and is associated with relatively low rates of dynamic recovery and higher 
than average rates of work hardening. Dynamic recrystallization commences only when a critical strain (also called the incubation strain) ${ }^{20)} \varepsilon_{c}$ is reached during hot deformation. This is somewhat less than the strain at the maximum stress, i.e. the maximum (or peak) strain $\varepsilon_{p}{ }^{21)}$ It is important to note that dynamic recrystallization produces both a texture and grain size distribution which are different from that of static recrystallization. ${ }^{22)}$ Another noteworthy point of the dynamically recrystallized structure concerns the "dislocation substructure". Here, a rather poorly recovered dislocation substructure develops in the initial stage of deformation; i.e. the cells have a relatively small size and more tangled walls compared to structures which have undergone a high degree of static recrystallization. This substructure, when retained to room temperature, leads to yield

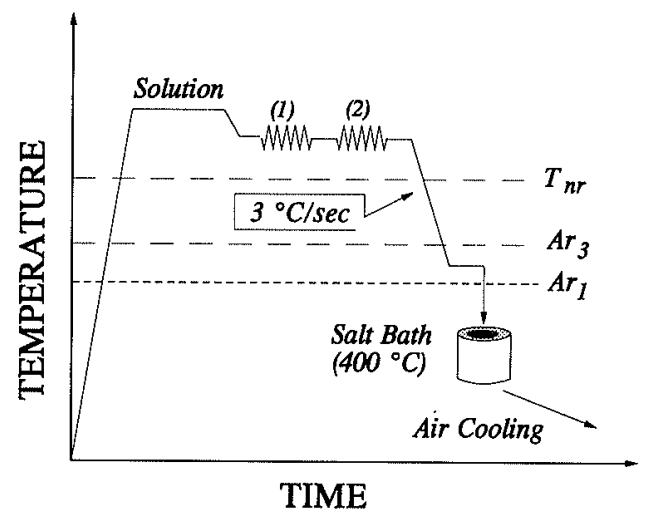

Fig. 1. Schematic diagram of heat and deformation schedule to generate different recrystallization conditions.

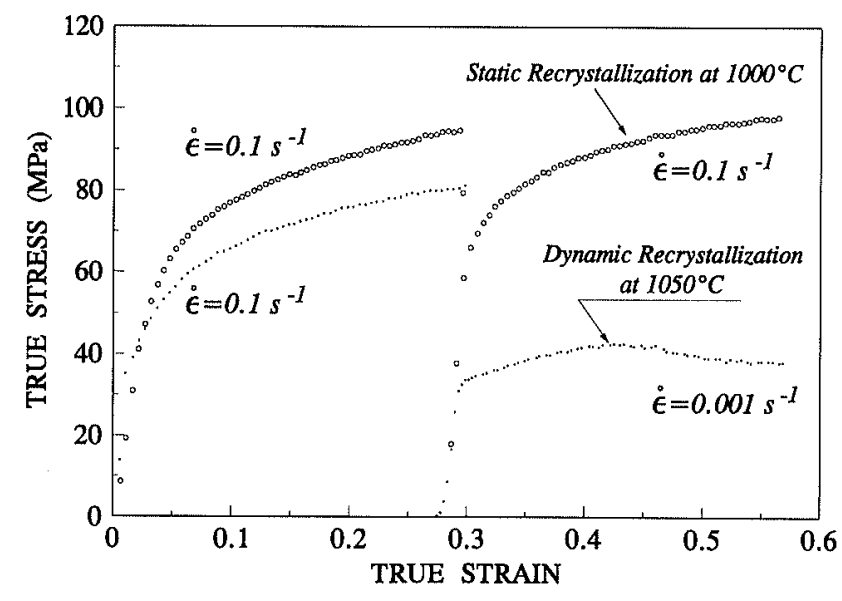

Fig. 2. Typical double-hit compression true stress-true strain curves of Reference-steel.
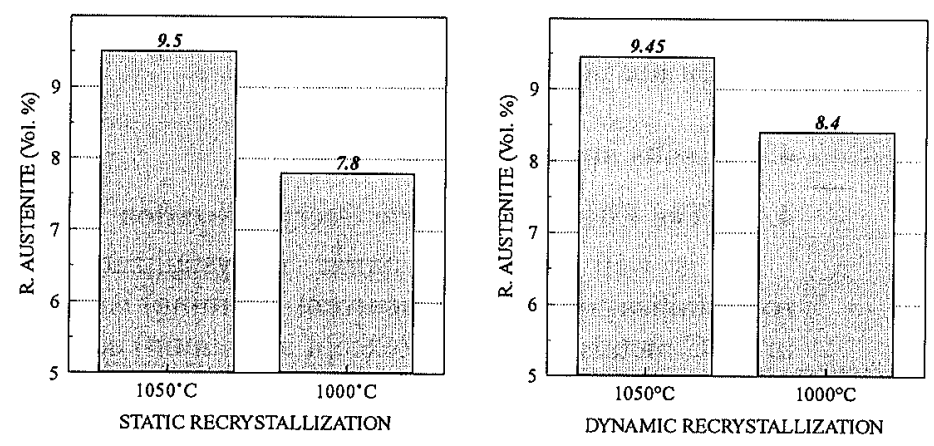

Fig. 4.

Variation of the $V_{R A}$ of $\mathrm{Nb}$-steel in th specimens undergone different recrystallization procedure. strengths higher than those of annealed materials. ${ }^{21)}$

\subsubsection{TMP Schedule}

To follow the effect of the dynamically recrystallized microstructure on the state of the retained austenite, the specimens were first solutionized (Fig. 1) to dissolve the $\mathrm{Nb}(\mathrm{CN})$ and $\mathrm{AlN}$ precipitates present in the initial microstructure and then processed by double hit compression at two different temperatures. In order to dynamically recrystallize the austenite, the second pass was carried out with a strain rate one to two orders of magnitude (depending on the temperature) lower than that of the first pass (Fig. 2). The specimen was then cooled down to a temperature below the $\mathrm{Ar}_{3}$ and held isothermally to form a known volume fraction of polygonal ferrite. This was followed by a salt bath quench, where the specimen was held isothermally for a predetermined duration at $400^{\circ} \mathrm{C}$ to transform the austenite to bainite (this temperature was shown to be the optimum temperature for maximizing the retained austenite volume fraction. ${ }^{4,6)}$ The specimen was then air cooled to room temperature.

For the $\mathrm{Nb}$-steel, the typical microstructure after the two compressive strains and a $3 \mathrm{~min}$ hold at $650^{\circ} \mathrm{C}$ is shown in Fig. 3. In this micrograph, the white areas are

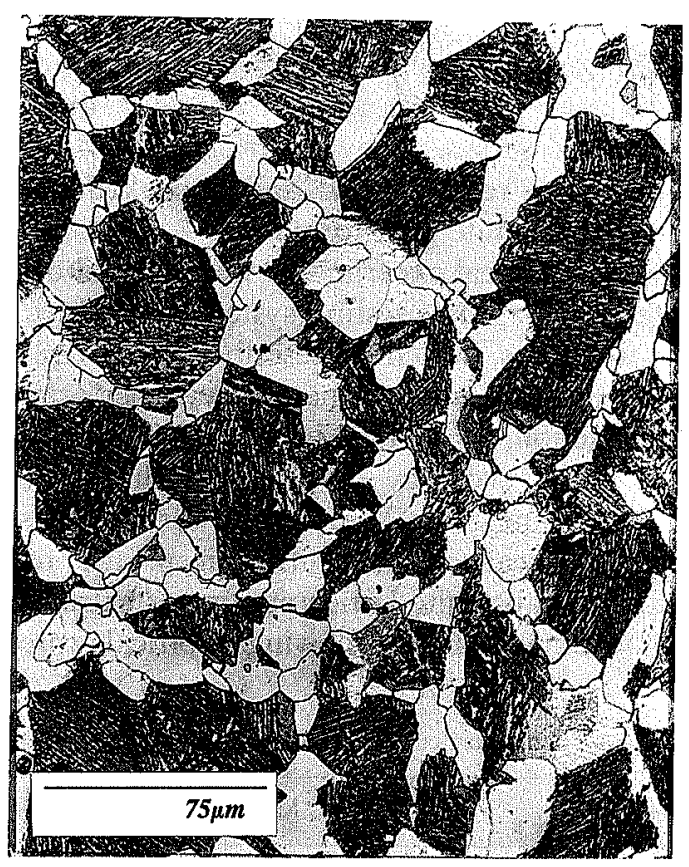

Fig. 3. Typical microstructure of Nb-steel after double-hit compression, and $3 \mathrm{~min}$ holding at $650^{\circ} \mathrm{C}$, followed by quenching into the salt bath $\left(400^{\circ} \mathrm{C}\right)$. 
polygonal ferrite, which have mostly nucleated at the prior austenite grain boundaries. The black regions are a combination of bainite, retained austenite and martensite. The recrystallized austenite grain sizes for steels $A$ and $B$ were found to be 40 and $45 \mu \mathrm{m}$, respectively.

\subsubsection{Microstructural and Mechanical Property Re- sults}

The results of microstructural examination to determine the distribution of retained austenite, using a modified color etching method, revealed that a wide range of retained austenite distribution and morphologies can be produced by the aforementioned TMP schedule. It was demonstrated ${ }^{6,23)}$ that retained austenite can be enclosed by (i) polygonal ferrite, (ii) bainite packets and (iii) upper and lower bainite platelets. In this case, they were mostly encompassed in upper bainite (i.e., pools (ii) and (iii)).

Figure 4 illustrates the variation of retained austenite volume fraction $\left(V_{R A}\right)$ for different conditions of static and dynamic recrystallization of $\mathrm{Nb}$-steel. The decrease of the temperature from 1050 to $1000^{\circ} \mathrm{C}$ in both cases results in a decrease in the $V_{R A}$. The level of $V_{R A}$ reduction in the case of dynamic recrystallization $(\sim 12 \%)$, however, is less than that of the static recrystallization case $(\sim 22 \%)$. Note that, the differences in prior austenite grain sizes (resulting from temperature and deformation variations in these cases), are in the range of $\pm 5 \mu \mathrm{m}$. Their effects on the subsequent transformation characteristics and on the retained austenite volume fraction are therefore negligible.

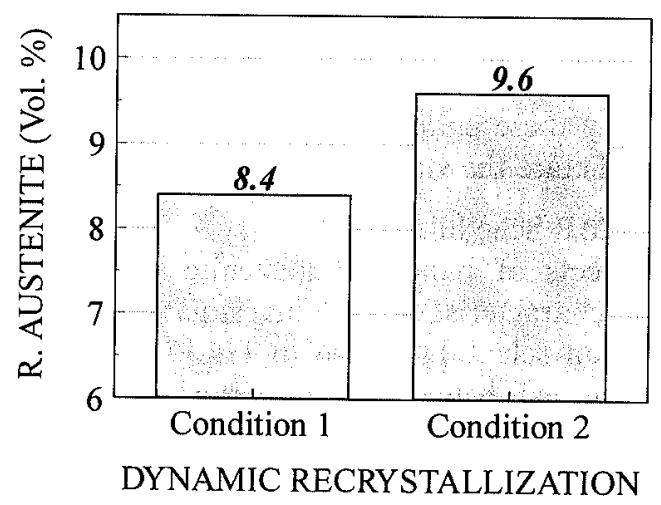

Fig. 5. Variation of the $V_{R A}$ of Nb-steel with different conditions of dynamic recrystallization.

Condition 1: Slow Cooling $\left(3^{\circ} \mathrm{C} / \mathrm{s}\right)$

Condition 2: Rapid Cooling $\left(10^{\circ} \mathrm{C} / \mathrm{s}\right)$
In order to observe the effect of dynamic recrystallization substructure, the dynamically recrystallized austenite was cooled down rapidly to the next step of processing. The result of this treatment is presented in Fig. 5. In the case of Condition 1 the specimen was cooled at $3^{\circ} \mathrm{C} / \mathrm{s}$ to a temperature below $A r_{3}$, and this was increased to $10^{\circ} \mathrm{C} / \mathrm{s}$ in the Condition 2 . As can be seen, the $V_{R A}$ was increased to a higher level. A comparison between the results of these two conditions indicates that the dynamically recrystallized austenite substructure, when retained to transformation temperatures, is more prone to retaining austenite. Microstructural examinations did not show any differences in the retained austenite size and distribution.

The mechanical properties of the specimens dynamically recrystallized at $1000^{\circ} \mathrm{C}$, followed by rapid and slow cooling, are shown in Fig. 6. As can be seen, the variation of total elongation follows the trend of the retained austenite volume fraction change. The UTS of the rapidly cooled material, even with higher amounts of retained austenite, is still higher than that of the slowly cooled structure.

\subsubsection{Discussion Concerning the Effects of Dynamic Recrystallization}

Since the prior austenite grain size was the same for both dynamically and statically recrystallized cases at $1000^{\circ} \mathrm{C}$, the two major differences between these austenite structures, are: (i) the level of solute $\mathrm{Nb}$ in $\mathrm{Nb}$ steel, and (ii) the substructures.

During dynamic recrystallization, austenite had undergone continuous straining with longer holding time period compared to the static case. As is well established, this will likely take the $\mathrm{Nb}$ out of solution through carbonitride precipitation, ${ }^{23)}$ i.e. the $\mathrm{Nb}$ level was lower in the dynamically recrystallized specimen. As is well known, solute $\mathrm{Nb}$ increases hardenability and decreases the $M_{s}$ temperature by solid solution strengthening of parent austenite. Therefore, for a given TMP schedule, austenite with more $\mathrm{Nb}$ in solution has a higher propensity to be retained or stabilized. ${ }^{23)}$ This can be firstly related to the inhibiting effect on the pearlite transformation (higher hardenability) and, secondly, through the presence of dissolved microalloying elements leading to solid solution strengthening in the austenite, therefore reducing the $M_{s}$ temperature. Accordingly, taking $\mathrm{Nb}$ out of solution by changing the processing parameters (e.g., decreasing the deformation temperature or increasing the hold time) decreases the retained
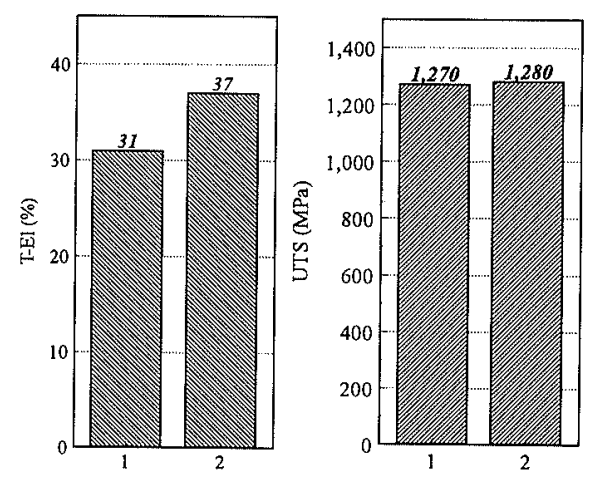

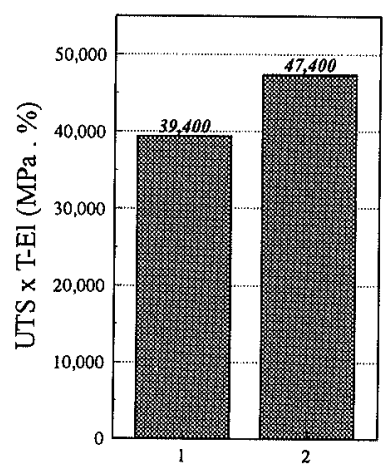

Fig. 6.

Mechanical properties of steel A for different conditions of dynamic recrystallization. ( 1 and 2 refer to Conditions 1 and 2 , respectively) 
austenite volume fraction at the end of processing. Therefore, having the austenite dynamically recrystallized at lower temperature should result in less retained austenite. On the other hand, the present results revealed that the faster cooled specimen retained a higher volume fraction of austenite. To rationalize these results, the different features of dynamic recrystallization substructure and their effects on the parent austenite stabilization (changes in the $M_{s}$ temperature) will be discussed below.

It has been shown that the dislocation density and distribution in a dynamically recrystallized microstructure can be retained to room temperature. ${ }^{21,24)}$ Thus, if the specimen is cooled quickly enough after dynamic recrystallization, the higher temperature substructures and defects will be included in the subsequent structure. This would be encouraged in the presence of $\mathrm{Nb}$, via dislocation pinning by precipitates and solute drag effects. The effect of substructures on the austenite stabilization (reducing $M_{s}$ temperature) can be discussed on the basis of the free energy change required for the martensite transformation to occur. ${ }^{6}$ ) The total free energy change can be considered to be made up of chemical and non-chemical contributions, i.e.:

$$
\Delta G_{\text {Chem }}^{\gamma \rightarrow \alpha^{\prime}}+\Delta G_{\text {Non-Chem }}^{\gamma \rightarrow \alpha^{\prime}}<0
$$

where $\Delta G_{\text {Chem }}^{\gamma \rightarrow \alpha^{\prime}}\left(=G_{\text {Chem }}^{\alpha^{\prime}}-G_{\text {Chem }}^{\gamma}\right)$ is the chemical free energy change associated with the formation of a unit volume of martensite. The term $\Delta G_{\text {Non-Chem }}^{\gamma \rightarrow \alpha^{\prime}}$ is a non-chemical free energy, and is a combination of the strain energy brought about by the volume change $\left(\Delta G_{\text {Strain }}\right)$, the increase in interfacial energy per mole of martensite particle of size $r\left(\Delta G_{r}\right)$ and the kinetic energy of the martensite plates (K.E., this term includes all the irreversible factors, such as heat, during the formation of martensite plates). But the transformation can only progress after a martensite embryo gains a critical size (the semi-thickness, $c$ ) given by Eq. (2):

$$
c=\frac{\frac{6 \Gamma_{s}}{d}-4 \sigma}{5 \Delta G_{\mathrm{Chem}}^{\gamma \rightarrow \alpha^{\prime}}}
$$

Where $d$ is the spacing between screw dislocations; $\sigma$ is the specific interfacial free energy of the austenite/ martensite interface, and $\Gamma_{s}$ is strain energy per unit length of random dislocation, which is given by:

$$
\Gamma_{s}=\frac{G b^{2}}{4 \pi}\left[\operatorname{Ln} \frac{r_{1}}{r_{0}}-1\right]
$$

Here, $G$ is the shear modulus, $b$ is the Burger's vector, $r_{0}$ is the radius of dislocation core and $r_{1}$ is one half the mean distance between dislocations. An increase in dislocation density should decrease $\Gamma_{s}$, via a decrease in $r_{1}$, which would reduce the value of $c$. The decrease of embryo size in this way leads to a higher interfacial energy per mole of martensite and consequently higher nonchemical free energy (the term $\Delta G_{\text {Non-Chem }}^{\gamma \rightarrow \alpha^{\prime}}$ in Eq. (1)). This increase in non-chemical free energy can be offset by an increase in chemical free energy, i.e. a lower $M_{s}$ temperature.
The effect of substructure has been explained by a different approach in Kajiwara's recent model, ${ }^{25)}$ in which plastic accommodation in austenite was considered to be a very important step in the nucleation event. Based on this model, in order for a martensite plate to be brought into existence from a potential nucleation site, three kinds of deformation must take place; these are, the "lattice deformation" which generates a martensite lattice from austenite, the "lattice invariant deformation" which produces an interface with no average distortion between the two phases (i.e., an invariant habit plane), and the deformation which accommodates the shape strain of the martensite plate. The shape strain of nucleating martensite (such as the shape strain of martensite plates during growth) must be accommodated by plastic deformation in austenite. Therefore any factors impeding the plastic accommodation, such as work hardening and small austenite particle size, suppress the transformation.

The present results therefore support the idea of an effect of substructure on austenite stabilization. By having some part of the substructure of the dynamically recrystallized specimen retained, the yield strength of the remaining austenite is increased, and the retained austenite volume fraction is higher.

\subsection{The Effect of Pancaking}

As is well established, the deformation of austenite in the no-recrystallization region results in the pancaking of austenite. The relevant microstructural features of pancaked austenite are an increase in dislocation density, formation of deformation bands, the destruction of the coherency of annealing twins with the matrix and the formation of ledge-like austenite grain boundaries. Both diffusional and non-diffusional transformations can be affected by these characteristics. This, in turn, can ultimately dictate the state of the retained austenite.

\subsubsection{TMP Schedule}

The effects of pancaked austenite on the retained austenite characteristics were investigated using the hot deformation schedule shown in Fig. 7. The specimens were deformed below the $T_{n r}$ after applying double hit deformation at $1050^{\circ} \mathrm{C}$. The rest of the process was the same as before, apart from the isothermal hold temperature in the two phase region. The latter was

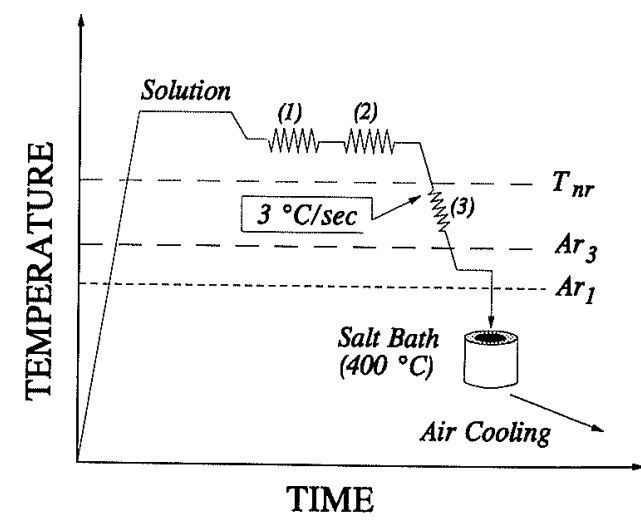

Fig. 7. The heat and deformation schedule used to investigate the effects of pancaking. 


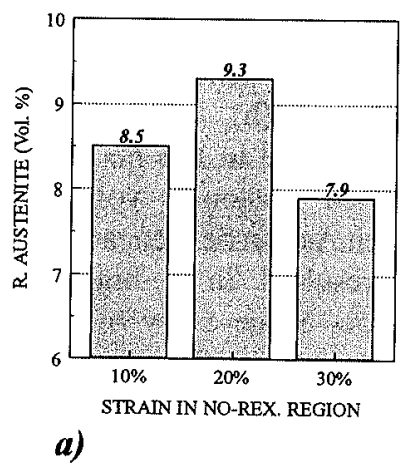

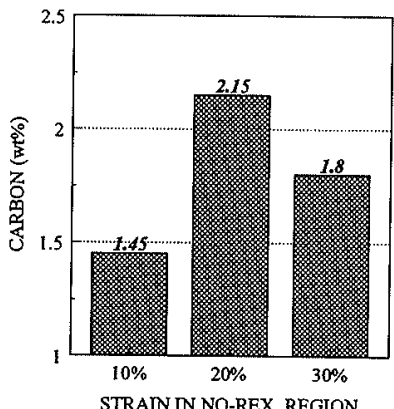

b)

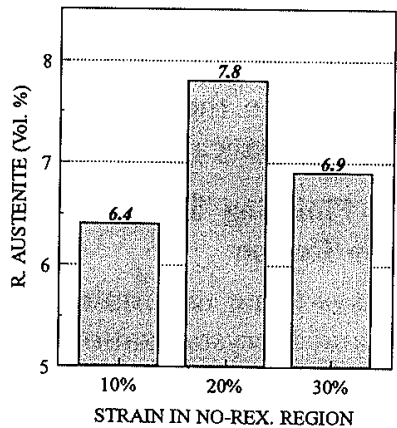

c)

Fig. 8. Variation of, (a) the $V_{R A}$ of $\mathrm{Nb}$-steel A, (b) the corresponding carbon content of $\mathrm{Nb}$-steel and (c) the $V_{R A}$ of Reference-steel, with strain in the no-recrystallization region.

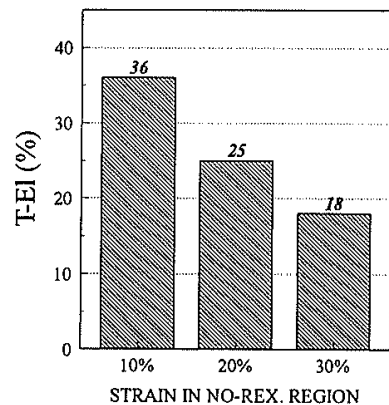

a)

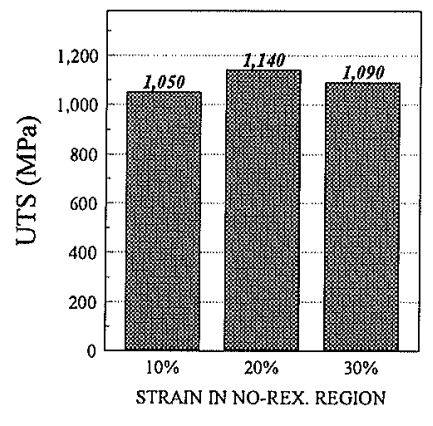

b)
Fig. 9. Mechanical properties of Nb-steel for different amount of strain in no-recrystallization region.

increased to $700^{\circ} \mathrm{C}$ in order to avoid pearlite formation during isothermal holding and cooling to bainitic region, since, as will be discussed later, undesired pearlite transformation can be encouraged by pancaking.

\subsubsection{Results}

Figure 8a) shows the variation of the retained austenite volume fraction with the amount of deformation in the no-recrystallization region for $\mathrm{Nb}$-steel. The amount of ferrite was kept the same for all cases $(30 \pm 3 \%)$. As can be seen there is a maximum $V_{R A}$ at about $20 \%$ strain. At this degree of deformation, the carbon level of the retained austenite is also maximised, (Fig. 8b)). Figure 8c) displays the variation of $V_{R A}$ with the same pancaking conditions for the Reference-steel (the amount of ferrite in these specimens was $40 \pm 4 \%$ ). Again, in this case, the maximum amount of retained austenite is attained at $20 \%$ strain.

The corresponding mechanical properties of the $\mathrm{Nb}$ steel microstructures are illustrated in Fig. 9. The total elongation does not change systematically with retained austenite volume fraction. The ultimate strength, however, attains its maximum at about $20 \%$ deformation, coinciding with the maximum $V_{R A}$.

\subsubsection{Discussion Concerning the Effect of Pancaking}

For both steels, the results revealed a maximum for the amount of retained austenite volume fraction when the strain in the no-recrystallization region was varied. This can be related to two opposing responses of the retained austenite volume fraction to changes in the strain in the no recrystallization region. They, in turn, can be divided into direct and indirect effects. The former is due to the strengthening of parent austenite and its stabilizing effect; the latter is a consequence of the change in the subsequent transformation characteristics of the prior austenite. These concepts will be clarified in the following paragraphs.

Since the lattice adjacent to the deformation structure is highly strained and severely distorted, these become preferred sites for ferrite and pearlite nucleation. They influence not only the kinetics of formation, but also the morphology and size of these transformation products. For a given composition, the effective nucleation area per unit volume $\left(S_{v}\right.$, which includes both grain boundaries and the boundaries of severely strained regions, mostly deformation bands) increases as the finishing temperature is decreased and total reduction below the no recrystallization temperature is increased. Therefore, for a given undercooling, the nucleation frequency increases with increasing total reduction. Consequently, the chance of undesired pearlite forming increases by increasing the total strain in the no-recrystallization region.

The increase of the retained austenite by straining in the no-recrystallization region is mainly due to the following. Prestraining (beyond a critical small strain) or work hardening of austenite (including the dynamic recrystallization substructure), increases the stability of austenite by lowering the $M_{s}$ temperature. ${ }^{26,27)}$ Thus, pancaking can be considered to decrease the $M_{s}$ temperature. Furthermore, recovery during pancaking could lead to subgrains with relatively high angle boundaries. This, in turn, can lead to martensitic transformation suppression, analogous to the austenite small particle effect. Finally, at higher temperatures and concurrent straining, the higher diffusion rate and segregation of alloying elements to the grain and deformation structure boundaries can lead to the poisoning of martensite embryo formation sites via localized strengthening of the austenite.

The decrease in the retained austenite volume fraction beyond a certain level of strain in the no-recrystallization region can be related to the undesired formation of pearlite. The precipitation of $\mathrm{Fe}_{3} \mathrm{C}$ during cooperative formation of pearlitic ferrite + carbide aggregates consumes the carbon and therefore decreases the stability of austenite. The latter leads to lower retained austenite 
at the end of process. The decrease in the total elongation by strain the the no-recrystallization region can be attributed to the increase in the rate of strain induced $\mathrm{Nb}(\mathrm{CN})$ precipitation via pancaking.

\subsection{The Effect of Finishing Temperature in the No- recrystallization Region}

Since there is always some restoration (i.e., dynamic and static recovery and recrystallization, depending on the state of strain and temperature) associated with hot deformation, the amount of strain energy accumulation (i.e. the density of dislocations in austenite) changes with the deformation-finish temperature. This, in turn, leads to a change in the kinetics of subsequent transformations. Figure $\mathbf{1 0}$ shows the variation of the retained austenite volume fraction with finishing temperature. The ferrite quantities for the specimens of the $\mathrm{Nb}$-steel and the Reference-steel are $16 \% \pm 2$ and $32 \% \pm 3$, respectively. The $\mathrm{Nb}$-steel does not encounter a significant change in $V_{R_{A}}$ after a $30 \%$ reduction at 900 and $800^{\circ} \mathrm{C}$. This is not true of the Reference-steel, where the decrease in finishing temperature resulted in a $15 \%$ increase in $V_{R A}$.

The corresponding mechanical properties of the above microstructures of $\mathrm{Nb}$-steel are shown in Fig. 11. Clearly, the total elongation is lower in the case of the specimen finished at $800^{\circ} \mathrm{C}$. The ultimate strengths, however, were not changed significantly.

The above findings can be rationalized as follows. The morphology, density and distribution of deformation structures are expected to change according to the deformation conditions in the no-recrystallization region. It is clear that the density of these defects in-

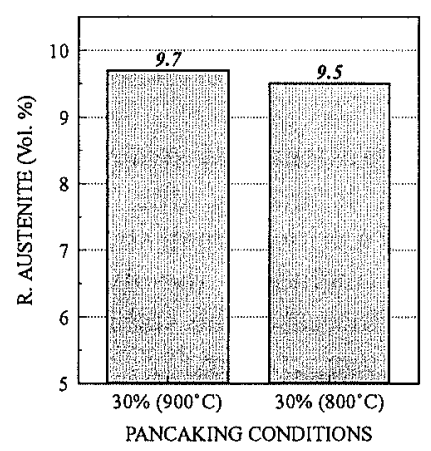

(a)

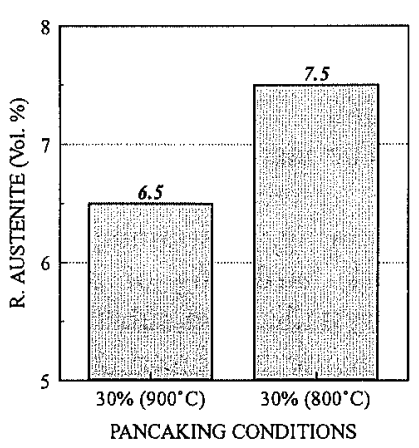

(b)
Fig. 10. Variation of the $V_{R A}$ with finshing temperature in the no-recrystallization region; (a) $\mathrm{Nb}$-steel $\mathrm{A}$, (b) Reference-steel.
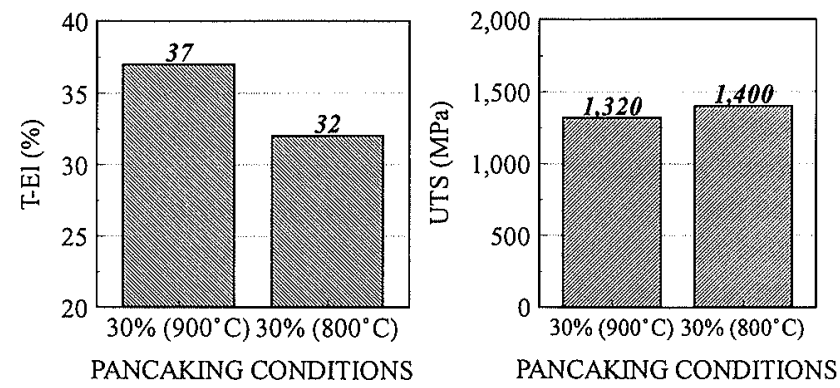

Fig. 11. Mechanical properties of Nb-steel for different finishing temperature. creases with increasing amounts of deformation and decreasing finishing temperature. The latter can be observed in Fig. 10(b), which illustrates the effect of finishing temperature in the no recrystallization region on the retained austenite volume fraction for the Reference-steel. As can be seen, a decrease in the finishing temperature resulted in a higher retained austenite volume fraction. Since every other relevant parameter was kept constant, this effect can be qualitatively linked to the higher density of defects in the deformation structure. In the case of the $\mathrm{Nb}$-steel, as can be seen in Fig. 11, the decrease in the finishing temperature did not change the retained austenite volume fraction. This is related to the presence of $\mathrm{Nb}$ (as a solute in austenite or precipitate) and its relatively strong effect on the retardation of the restoration processes, even at higher temperatures.

\subsection{Conclusions}

The effects of two important TMP parameters, i.e. the dynamic recrystallization substructure and the level of strain in the austenite no-recrystallization region, on the state of retained austenite and the corresponding mechanical properties of two grades of $\mathrm{Si}-\mathrm{Mn}$ TRIP steels were examined. This study resulted in the following conclusions:

(1) The dynamically recrystallized austenite substructure, when retained to transformation temperatures, is more prone to retaining austenite (more $V_{R A}$ ). The variation of total elongation correlates with that of the retained austenite volume fraction change. The UTS in the rapidly cooled material, which retained the dynamically recrystallized austenite substructure, is still higher than that of the slowly cooled structure, even though the amount of retained austenite is higher in the former.

(2) TMP conditions which promoted $\mathrm{Nb}(\mathrm{CN})$ precipitation resulted in a decrease in the $V_{R A}$. This was attributed to a reduction of $\mathrm{Nb}$ in solid solution and therefore a decrease in parent austenite stability.

(3) The variation of the retained austenite volume fraction with strain in the no-recrystallization region always exhibited a maximum. For both the $\mathrm{Nb}$-steel and Reference-steel, although the ferrite quantity was not the same, the maximum $V_{R A}$ was observed at about $20 \%$ strain. The total elongation, in the case of $\mathrm{Nb}$-steel, does not change systematically with the retained austenite volume fraction. The ultimate strength, however, attains its maximum at about $20 \%$ deformation, coinciding with the maximum $V_{R A}$.

(4) The decrease in the finishing temperature resulted in a higher retained austenite volume fraction in the Reference-steel. This effect was attributed to the higher density of defects in the deformation structure. In the case of the $\mathrm{Nb}$-steel, the decrease in the finishing temperature did not change the retained austenite volume fraction. This was correlated to the presence of $\mathrm{Nb}$ and its effect on the retarding the restoration processes, even at higher temperatures. 


\section{Acknowledgements}

The financial support of the Canadian Steel Industry Research Association and the Natural Sciences and Engineering Research Council of Canada is gratefully acknowledged. A. Zarei-Hanzaki is also grateful to the Ministry of Culture and Higher Education of the Islamic Republic of Iran for the provision of a scholarship.

\section{REFERENCES}

1) V. F. Zackay, E. R. Parker, D. Fahr and R. Bush: Trans. Am. Soc. Mat., 60 (1967), 252

2) K. I. Sugimoto, N. Usui, M. Kobayashi and S. I. Hashimoto: ISIJ Int., 32 (1992), 1311.

3) O. Matsumura, Y. Sakuma and H. Takechi: ISIJ Int., 32 (1992), 1041 .

4) Y. Sakuma, S. Matsumura and H. Takechi: Metall. Trans., 22A (1991), 489.

5) K. I. Sugimoto, M. Misu, M. Kobayashi and H. Shirasawa: ISIJ Int., 33 (1993), 775.

6) A. Zarei-Hanzaki: Ph.D. Thesis, McGill University, (1994)

7) I. Tsukatani, S. Hashimoto and T. Inoue: ISIJ Int., 31 (1991), 992.

8) A. Zarei-Hanzaki, P. D. Hodgson and S. Yue: 33rd Mechanical Working and Steel Processing Conference, Iron and Steel Soc. of AIME, XXIX, St. Louis, (1992), 459.

9) B. D. Cullity: Elements of X-Ray Diffraction, Second Ed., Addison-Wesley Publishing Company, Inc., Mass., (1978).
10) G. E. Lucas: Metall. Trans., 21A (1990), 1105.

11) A. Zarei-Hanzaki, R. Pandi, P. D. Hodgson and S. Yue: Metall. Trans., 24A (1993), 2657.

12) W. Steven and A. G. Haynes: JISI, 183 (1956), 349.

13) C. L. Magee: Metall. Trans., 2 (1971), 2419.

14) O. A. Ankara: JISI, 208 (1970), 819.

15) E. M. Breinan and G. S. Ansell: Metall. Trans., 1 (1970), 1513.

16) V. F. Bhandarkar, V. F. Zackay and E. R. Parker: Metall. Trans., 3 (1972), 2619.

17) R. F. Vyhnal and S. V. Radcliffe: Acta Metall., 15(1967), 1475.

18) G. Krauss and M. Cohen: Trans. AIME, 227 (1963), 278.

19) B. Edmonson and T. Ko: Acta Metall., 2 (1954), 235.

20) A. K. Sinha: Ferrous Physical Metallurgy, Butterworths, Stoneham, (1989), 614

21) H. J. McQueen and J. J. Jonas: Treatise on Materials Science and Technology, 6 (1975), 393.

22) T. Sakai, M. G. Akben and J. J. Jonas: Thermomechanical Processing of Microalloyed Austenite, Conf. Proc., TMS-AIME, Warrendale, Pa., (1982), 237.

23) A. Zarei-Hanzaki, P. D. Hodgson and S. Yue: The manuscript submitted to Metall. Trans. A, (1994).

24) T. Sakai, Y. Nagao, M. Ohashi and J. J. Jonas: Mater. Sci. Technol., 2 (1986), 659

25) S. Kajiwara: Metall. Trans., 17A (1986), 1693.

26) T. Maki: Physical Metallurgy of Direct-Quenched Steels, TMS Publications, Warrendale, Pennsylvania, (1992), 3.

27) A. T. Davenport: Hot Deformation of Austenite, AIME, New York, (1977), 517. 